\title{
Imagem cinematográfica e pensamento: imagem-afeção na confluência das teorias de Peirce e Deleuze
}

\section{Cinematographic image and thought: affection-image at the confluence of the of Peirce's and Deleuze's theories}

\author{
Maria Ogécia Drigo \\ Universidade de Sorocaba \\ $<$ maria.ogecia@gmail.com>
}

\section{Como citar este artigo (How to cite this article):}

DRIGO, Maria Ogécia. Imagem cinematográfica e pensamento: imagem-afeção na confluência das teorias de Peirce e Deleuze. Revista Famecos, Porto Alegre, v. 25, n. 2, p. 1-19, maio, junho, julho e agosto de 2018: ID27989. DOI: http://dx.doi.org/10.15448/1980-3729.2018.2.27989.

\section{RESUMO}

Este artigo apresenta resultados de pesquisa, que trata da relação entre pensamento e imagem cinematográfica, considerando-se as teorias elaboradas por Gilles Deleuze, na confluência com as de Charles Sanders Peirce. Entre as modalidades de imagem-movimento, conceito desenvolvido por Deleuze no livro A Imagem-movimento Cinema 1, neste artigo, prioriza-se a imagem-afeção. Com o propósito de compreender tal conceito e explicitar o papel deste no pensamento, trata-se, em linhas gerais, do conceito de imagem-movimento e de suas divisões, mas acopladas às categorias fenomenológicas peirceanas; em seguida, classifica-se a imagem-afeção, a partir de definições e da taxionomia advindas da gramática especulativa, um dos ramos da semiótica ou lógica desenvolvida por Peirce, destacando-se os diversos tipos de ícone. A importância deste artigo está em colocar em evidência o potencial das teorias peirceanas, que fluem com as deleuzeanas, para a compreensão do pensamento, ou de imagens em movimento.

Palavras-chave: Deleuze/Peirce. Imagem cinematográfica. Imagemafeção.

\section{ABSTRACT}

This paper presents results of a research, which addresses the relation between thought and cinematographic images, from theories developed by Deleuze at the confluence with Peirce's theories. Among the kinds of the movement-image, a concept developed by Deleuze in Movement Image - Cinema 1 - for this paper, one has focused the affection image. Aiming to understand such concept and to explicit its role in the thought, focus on reflections about the movement image concept and its subdivisions, but connected with phenomenological categories established by Peirce. Besides that, it will be classified the affection-image, based on definitions and taxonomy of signs extracted from the speculative grammar, one of the branches of semiotics or logic, highlighting the different kinds of icon. The importance of this paper lies in emphasizing the potential of Peirce's theories which flow with Deleuze's theories, for the understanding of thought or of moving images. 


\section{Introdução}

Este artigo tem como tema a relação entre imagens cinematográficas e o pensamento, construída no fluxo com as teorias peirceanas, principalmente as categorias fenomenológicas e parte da taxionomia dos signos, e apresentada em Deleuze (2009), obra intitulada A imagem-movimento Cinema 1. Nele, prioriza-se o conceito de imagem-afeção, uma entre as três modalidades da imagem-movimento, com o objetivo de compreender as especificidades da imagem-afeção e o seu papel no pensamento.

Asreflexõesapresentadassãoresultados de pesquisa em desenvolvimento, que tem como corpus as obras: Deleuze (2009) - A imagem-movimento Cinema 1 - e Deleuze (2013) - A imagem-tempo Cinema 2-, e como objetivo, inicialmente, a compreensão de como o filósofo articula os conceitos de imagem-movimento e imagem-tempo aos conceitos advindos da fenomenologia e da gramática especulativa, um dos ramos da semiótica ou lógica', proposta por Charles Sanders Peirce. Posteriormente, propõe-se a realização de um inventário das contribuições dos conceitos deleuzeanos mencionados para a compreensão do pensamento, bem como a sugestão de estratégias metodológicas para análise fílmica, ou de imagens em movimento, conjeturando-se sobre a possibilidade de que a análise fílmica pode ir além da textual, narratológica ou psicanalítica. Vale destacar que em Drigo (2016) trata-se da imagem-percepção, outra modalidade de imagem-movimento.

Machado (2009), em suas análises sobre as três modalidades de imagemmovimento, privilegia as teses de Bergson sobre o movimento, bem como os conceitos de imagem e percepção propostas pelo mesmo filósofo e enfatiza também que a classificação das imagens e dos signos apresentados por Deleuze "tem pouco a ver com as de Peirce" (Machado, 2009, p. 256). Nesse sentido, considera-se pertinente investigar como os pensamentos peirceano e deleuzeano colocam-se num mesmo fluxo.

1 Em relação à semiótica ou lógica, Peirce (1931a, p. 57, tradução nossa) explica que "todo pensamento se por meio de signos, logo, a lógica deve ser vista como a ciência geral dos signos". (No original): All thought being performed by means of signs, logic may be regarded as the science of the general laws of signs. Este ramo da Ciência Normativa "tem três divisões: 1. Gramática especulativa, ou a teoria da natureza e significados dos signos, que podem ser ícones, índices e símbolos; 2. Lógica Crítica, que classifica os argumentos e determina o grau de validade e força de cada um; 3. Metodêutica, que estuda os métodos que deveriam ser seguidos em qualquer investigação, na exposição e na aplicação da verdade. Cada divisão depende da que a precede" (Peirce, 1931a, p. 57-58, tradução nossa). (No original): It has three branches: 1, Speculative Grammar, or the general theory of the nature and meanings of signs, whether they be icons, indices, or symbols; 2, Critic, which classifies arguments and determines the validity and degree of force of each kind; 3 , Methodeutic, which studies the methods that ought to be pursued in the investigation, in the exposition, and in the application of truth. Each division depends on that which precedes it. 
A seguir, em linhas gerais, apresenta-se o conceito de imagem-movimento e trata-se das suas três componentes: imagem-percepção, imagem-ação e imagem-afeção, com ênfase na imagem-afeção.

\section{Imagem-movimento}

O conceito de imagem-movimento fundamenta-se nas teses do movimento e nas concepções de imagem e percepção que constam na obra Matéria e Memória, Bergson (1999). A partir de tais teorias, conforme Deleuze (2009, p. 11), não era mais possível opor o "movimento como realidade física no mundo exterior à imagem como realidade psíquica na consciência", ou seja, tais teorias demonstraram a identidade entre imagem e movimento e, mais especificamente, entre imagem-movimento e matéria.

Inicia-se com as três teses bergsonianas sobre o movimento. A primeira refere-se ao movimento, o ato de percorrer, como distinto do espaço percorrido. Eles são irredutíveis, embora haja uma tendência em se reconstituir o movimento a partir do espaço. Não é possível "reconstituir o movimento (...) com uma sucessão de posições no espaço ou uma sucessão de momentos, de instantes, no tempo; não se pode reconstituir o movimento com 'cortes' imóveis" (Machado, 2009, p. 249). Essa noção de movimento, que tem seu cerne no embate entre o discreto e o contínuo, levou Bergson a criticar o cinema. No entanto, para Deleuze, conforme Machado (2009, p. 249),

\section{essa crítica significa que o cinema leva ao extremo a ilusão da falsa reconstituição do movimento, pois o que apresenta como imagens são cortes instantâneos submetidos à sucessão de um tempo uniforme e abstrato: o tempo do movimento da câmera.}

O cinema, nesta perspectiva, ao reconstituir o movimento com fotografias imóveis, ou cortes imóveis, não capta o movimento real com sua concreta duração. A segunda tese distingue duas maneiras de pensar o movimento. Um é advindo do pensamento aristotélico, no qual o movimento é a passagem de uma a outra forma imóvel, tal como uma ordem de pose, ou de instantes privilegiados. A outra advém da ciência moderna, que remete o movimento a um instante qualquer, ou a qualquer momento da sua trajetória. Deleuze considera que o cinema "reproduz o movimento em função de um momento qualquer, isto é, em função de instantes quaisquer equidistantes escolhidos de modo a dar a impressão de continuidade" (Machado, 2009, p. 252). Esclarece ainda o mesmo autor que, assim como Bergson defende a ideia de que a ciência moderna espera uma filosofia que pense o tempo enquanto duração, produção do novo, Deleuze sugere que a filosofia precisa valer-se de uma nova arte que 
também realize tal tarefa. Daí a importância da terceira tese de Bergson, para fundamentar o caminhar de Deleuze (2009).

Na terceira tese, o movimento é considerado como um corte móvel da duração, o que implica em mudança qualitativa, pois exprime uma duração como realidade mental. Esclarece Machado (2009, p. 252), que "o movimento é uma translação,mudançadeposiçãonoespaço,massemprequehátranslaçãodepartes no espaço também há mudança qualitativa num todo, ou na duração". O todo é aberto, o que implica em mudança incessante que faz surgir algo novo, que dura.

O movimento, para Bergson, de um lado "é aquilo que se passa entre objetos ou partes, por outro é aquilo que exprime a duração ou o todo" (Deleuze, 2009, p. 27). Os objetos ou partes de um conjunto são denominados cortes móveis e o "movimento estabelece-se entre esses cortes e relaciona os objetos ou partes com a duração de um todo que muda, exprime portanto a mudança do todo relativamente aos objetos e ele próprio é um corte móvel da duração" (Deleuze, 2009, p. 27). Assim sendo, não há somente imagens instantâneas, ou cortes imóveis do movimento, mas imagens-movimento, que são cortes móveis da duração. O plano é a imagem-movimento, é um corte móvel de uma duração, uma vez que refere o movimento a um todo que muda.

Ao elaborar uma classificação das imagens cinematográficas, segundo Machado(2009, p.247), a tese deDeleuzeéa de que"ocinema pensa com imagensmovimento e imagens-tempo, as primeiras caracterizando o cinema clássico, as segundas, o cinema moderno". A primeira, a imagem-movimento, mostra o tempo através do movimento, isto é, representa o curso empírico do tempo, enquanto a imagem-tempo, para Machado (2009, p. 248), "dá uma apresentação direta do tempo, uma apresentação do tempo puro, livre do movimento".

Como um filme não é feito com um único tipo de imagem, a composição, o agenciamento, a conexão dos diversos tipos de imagem-movimento é essencial. Neste sentido, o cinema clássico, da imagem-movimento, define-se pela montagem, que dá uma imagem indireta do tempo ao encadear os diversos tipos de imagem em função da ação. Além disso, um filme apresenta sempre a predominância de um tipo de imagem (Machado, 2009, p. 258).

O que cabe à montagem, segundo Deleuze (2009, p. 54), "é a imagem indireta do tempo, da duração. Não um tempo homogêneo, ou uma duração espacializada, como a que Bergson denuncia, mas uma duração e um tempo efetivos que decorrem da articulação das imagens-movimento".

Conforme Deleuze (2009), a imagem-movimento divide-se em imagempercepção, imagem-ação e imagem-afecção. Esta divisão está em concordância com a ideia de que a percepção e a linguagem distinguem corpos, qualidades e 
ações. O corpo substitui o movimento pela ideia de um sujeito que o executaria, ou ainda de um objeto que o sofreria, de um veículo que o transportaria; a qualidade, por sua vez, substitui o movimento pela ideia de um estado que persiste enquanto não lhe suceder outro e, por fim, a ação substitui o movimento pela ideia de um lugar provisório para onde ele se dirige ou de um resultado que ele obtém. As imagens, na sua materialidade, para Deleuze, não são coisas concebidas como corpos, mas como qualidades, ou ações.

Inicia-se com a imagem-percepção, com explicações que constam em Drigo (2016). Faz-se necessário distinguir, segundo as teorias de Bergson, no processo perceptivo, a diferença entre a coisa e a percepção da coisa. "A coisa é a imagem tal como ela é em si, tal como se refere a todas as outras imagens das quais sofre integralmente a ação e sobre as quais reage imediatamente" (Deleuze, 2009, p. 103), enquanto a percepção da coisa, por sua vez, conforme Deleuze (2009, p. 103-104), "é a mesma imagem referida a uma outra imagem especial que a enquadra e que só retém dela uma ação parcial e só reage a ela mediatamente". A percepção é um processo que envolve mediação e a coisa é percepcionada segundo os interesses de quem a percepciona. Isso corresponde ao primeiro momento material da subjetividade: a subtração. Nas palavras de Deleuze (2009, p.104):

\footnotetext{
Por necessidade ou interesse deve entender-se as linhas e pontos que retemos da coisa em função da nossa face receptora e as ações que selecionamos em função das ações retardadas de que somos capazes. O que é uma maneira de definir o primeiro momento material da subjetividade: ela é subtrativa, ela subtrai da coisa o que não lhe interessa. Mas, inversamente, é preciso nesse caso que a própria coisa se apresente em si como uma percepção, e como uma percepção completa, imediata, difusa. A coisa é imagem e, a esse título, percepciona-se a si mesma e percepciona todas as outras na medida em que lhes sofre a ação e reage a esta em todas as suas partes.
}

No entanto, além da subtração há a ação, uma resposta imprevista, que só é possível porque ao percepcionar a coisa, uma face recebeu uma excitação privilegiada e as demais foram eliminadas, o que "equivale a dizer que toda percepção é antes de mais sensório-motora" (Deleuze, 2009, p. 105). A percepção, conforme Deleuze (2009, p. 106), "refere o movimento a corpos (substantivos), quer dizer, a objetos rígidos que vão servir de móveis ou de movidos, a ação refere o movimento a atos (verbos)". Mas, há outra modalidade de imagem-movimento, a imagem-afeção, que refere o movimento à qualidade e corresponde ao terceiro aspecto material da subjetividade. 
A afeção é aquilo que ocupa o intervalo, aquilo que o ocupa sem o encher ou o tapar. Ele surge no centro da indeterminação, isto é, no sujeito, entre uma percepção sob certos aspectos perturbante e uma ação hesitante. Ela é uma coincidência do sujeito e do objeto, ou a maneira como o sujeito se percepciona a si mesmo, ou antes, faz a experiência de si ou se sente "de dentro" (terceiro aspecto material da subjetividade). Ela refere o movimento a uma "qualidade" como estado vivido (adjetivo) (Deleuze, 2009, p. 106).

A imagem-afeção, segundo Deleuze (2009, p. 107) marca "a coincidência do sujeito e do objeto numa qualidade pura. Éesse o último avatar da imagem-movimento".

As três modalidades da imagem-movimento - imagem-percepção, imagem-ação, imagem-afeção - estão presentes num filme.

Nunca um filme é feito de um único tipo de imagem: chamase precisamente montagem à combinação das três variedades. A montagem (num dos seus aspectos) é o agenciamento das imagens-movimento e portanto o interagenciamento das imagenspercepção, das imagens-afecção e das imagens-ação. (...) Aos três tipos de variedades pode-se fazer corresponder três tipos de planos espacialmente determinados: o plano de conjunto será sobretudo uma imagem-percepção, o plano médio uma imagem-ação e o grande plano uma imagem-afecção (Deleuze, 2009, p. 113).

Depois de tratar dos três tipos de imagem-movimento, Deleuze faz a leitura desses três tipos valendo-se das categorias fenomenológicas e da classificação dos signos de Peirce. Neste artigo, prioriza-se o percurso do filósofo em relação à imagem-afeção.

\section{Imagem-afeção}

Para Deleuze (2009, p. 153), o afeto é indivisível, "mas as combinações singulares que forma com outros afetos formam por sua vez uma qualidade indivisível que só se dividirá mudando de natureza. $O$ afeto é independente de todo espaço-tempo determinado". Ainda, conforme Deleuze (2009, p. 153), "o afeto é impessoal e distingue-se de todo estado de coisas individuado: o que não o impede de ser singular e de poder entrar em combinações ou conjunções singulares com outros afetos".

A imagem-afeção, para Deleuze, é o grande plano e o grande plano é o rosto e que, para Eisenstein, o grande plano "não era apenas um tipo de imagem entre outras, mas antes dava uma leitura afetiva de todo o filme. Isto é verdade na imagem-afecção:é ao mesmo tempo um tipo de imagem e uma componente de todas as imagens" (Deleuze, 2009, p. 137). 
Deleuze dá como exemplo de rosto, algo que não é um rosto, mas um relógio de parede apresentado em grande plano, várias vezes. Segundo o filósofo, tal imagem exibe, de um lado, os ponteiros animados, em movimento; de outro, "um mostrador como superfície receptora imóvel, placa receptiva de inscrição, suspensão impassível: é unidade refletora e refletida" (Deleuze, 2009, p. 137).

A definição bergsoniana de afeto, conforme explica Deleuze, envolve esses dois aspectos: uma unidade refletora imóvel e movimentos intensos expressivos. Deleuze (2009, p. 137-138) esclarece que Bergson definia a afeção como "uma tendência motriz sobre um nervo sensível", ou seja, "uma série de micro-movimentos sobre uma placa nervosa imobilizada".

Quando uma parte do corpo teve de sacrificar o essencial da sua motricidade para se tornar o suporte de órgãos de recepção, estes já terão principalmente tendências para o movimento ou micromovimentos capazes, para um mesmo órgão ou de um órgão para outro, de entrar em séries intensivas. O móvel perdeu seu movimento de extensão e o movimento tornou-se movimento de expressão. (...) Mas não é isto a mesma coisa que um Rosto em pessoa? (Deleuze, 2009, p. 137-138).

Mas, quando uma coisa adquire o caráter de rosto, ou seja, quando uma coisa apresenta-se rostizada? Isso se dá exatamente quando a coisa apresenta dois polos: uma superfície refletora e micro-movimentos intensivos.

O rosto pode vir por traços que escapam do seu contorno e que adquirem autonomia diante de outros. Este é o rosto intensivo e que exprime, segundo Deleuze (2009, p. 141), "um poder puro, isto é, se define por uma série que nos faz passar de uma qualidade para outra". Ou, o rosto pode vir com os traços agrupados compondo um pensamento fixo, eterno, mas sem devir. Trata-se do rosto reflexivo ou refletor, que não pensa em qualquer coisa, mas que, conforme Deleuze (2009, p. 141), exprime uma "qualidade pura, isto é, um 'qualquer coisa' comum a vários objetos de natureza diferente." Os dois polos do rosto podem ser visualizados no diagrama (Quadro 1). 
Quadro 1 - Os dois polos do rosto

\begin{tabular}{|c|c|}
\hline Nervo sensível & Tendência motriz \\
\hline Placa receptível imóvel & Micro-movimentos de expressão \\
\hline Contorno rostizante & Traços de rostidade \\
\hline Unidade refletora & Série intensiva \\
\hline Wonder (admiração, espanto) & Desejo (amor-ódio) \\
\hline Qualidade & Poder \\
\hline $\begin{array}{c}\text { Expressão de uma qualidade comum a } \\
\text { várias coisas diferentes }\end{array}$ & $\begin{array}{c}\text { Expressão de um poder que passa de } \\
\text { uma qualidade para outra }\end{array}$ \\
\hline
\end{tabular}

Fonte: Deleuze (2009, p. 141-142)

Vale lembrar que o rosto é uma"placa nervosa porta-órgãos que sacrificou o essencial da sua mobilidade global e que recolhe ou exprime ao ar livre todos os tipos de pequenos movimentos locais que o resto do corpo mantém habitualmente escondidos" (Deleuze, 2009, p. 138). O grande plano não trata do rosto ou não se submete a ele, ou seja, "não há grande plano de rosto, o rosto é em si mesmo grande plano, o grande plano é por si mesmo rosto, e ambos são o afeto, a imagem-afeção" (Deleuze, 2009, p. 138).Esclarece ainda o mesmo autor, que o grande plano não seria uma parte do todo, também não é um objeto de um conjunto em que ele está inserido, mas que ele adquire o caráter de entidade ao ser abstraído de suas coordenadas espacio-temporais, ou seja, é algo que passa a ser poder ou qualidade. Aqui Deleuze define ícone. Nas suas palavras:

O afeto é a entidade, isto é, o Poder ou a Qualidade. É um exprimido: o afeto não existe independentemente de qualquer coisa que o exprime, embora se distinga completamente dela. Aquilo que o exprime é um rosto ou um equivalente de rosto (um objeto rostizado), ou até uma proposição, como veremos adiante. Chama-se "Ícone" ao conjunto do exprimido e sua expressão, do afeto e do rosto. Há portanto ícones de traço e ícones de contorno, ou antes, todos os ícones tem estes dois polos: é o signo de composição bipolar da imagem-afecção (Deleuze, 2009, p. 151).

Em outro momento, Deleuze retoma a noção de ícone.

E a chuva também não é o conceito de chuva, nem o estado de um tempo e de um lugar chuvosos. É um conjunto de singularidades que apresenta a chuva tal como ela é em si, puro poder ou qualidade que conjuga sem abstração todas as chuvas possíveis e compõe o espaço qualquer correspondente. É a chuva como afeto, e nada se opõe mais 
a uma ideia abstrata ou geral, embora não esteja atualizada num estado de coisas individual (Deleuze, 2009, p. 171).

No entanto, para Deleuze, os poderes e as qualidades podem vir atualizados, encarnados em estado de coisas. Quando atualizados, o poder torna-se ação; a qualidade torna-se 'quale' do objeto; o afeto torna-se sensação, sentimento, emoção ou até pulsão numa pessoa enquanto o rosto torna-se caráter, ou máscara da pessoa. Neste caso, não se está no domínio da imagemafeção, mas da imagem-ação.

Conforme Deleuze (2009, p. 153), "as imagens-afeções, no sentido restrito, remetem apenas para a primidade". Deleuze (2009, p. 152) menciona que para qualquer classificação das imagens e dos signos, Peirce distinguia entre dois tipos de imagens, as que chamava 'Primidade' e 'Segundidade"'.

Observa-se como o filósofo francês explica duas das categorias: a primeridade e a segundidade.

A segundidade estava aí onde houvesse dois por si mesmo: aquilo que é tal como é por relação com um segundo. Tudo o que só existe opondo-se, por e num duelo, pertence pois à segundidade: esforço-resistência, ação-reação, excitação-resposta, situaçãocomportamento, indivíduo-meio... É a categoria do real, do atual, do existente, do individuado. E a primeira figura da segundidade é já aquela em as qualidades-poderes se tornam "forças", isto é, se atualizam em estados de coisas particulares, em espaços-tempos determinados, em meios geográficos e históricos, em agentes coletivos ou pessoas individuais. É aí que nasce e se desenvolve a imagem-ação (Deleuze, 2009, p. 151).

Em relação à primeiridade, embora considere 'bastante estranhos' os exemplosdePeirce, ofilósofofrancêstececomentáriossobreaprimeiridade,assim como os da segundidade, que vão ao encontro das explicações dadas por Peirce.

Peirce não esconde que a primeiridade é difícil de definir, por ser mais sentida do que concebida: ela concerne o novo na experiência, o fresco, o fugaz e porém eterno. (...) São qualidades ou poderes considerados por si mesmos, sem referência a nenhuma outra coisa, independentemente de toda a questão sobre sua atualização. É aquilo que é tal como é por si mesmo e em si mesmo (Deleuze, 2009, p. 152).

Deleuze vincula a primeiridade à consciência, que também corresponde à consciência de qualidade ou da primeiridade, tal como Peirce propõe.

Se quisermos, é uma consciência imediata e instantânea, tal como está implicada por toda a consciência real que, essa, nunca é imediata nem instantânea. Não é uma sensação, um sentimento, uma ideia, 
mas a qualidade de uma sensação, de um sentimento ou de uma ideia possíveis. A primeiridade é portanto a categoria do possível sem o atualizar mas fazendo dele mesmo assim um modo completo (Deleuze, 2009, p. 152).

Conclui, então, que "a imagem-afecção é exatamente isso: é a qualidade ou o poder, é a potencialidade considerada por si mesma enquanto exprimida. $O$ signo correspondenteépoisa expressão, nãoa atualização"(Deleuze, 2009, p. 152).

Em seguida, buscam-se ideias peirceanas, notadamente as categorias fenomenológicas, definição de signo eas três primeiras tricotomias, ou a classificação do signo na relação com o seu fundamento, com o objeto imediato e com o interpretante gerado. Por fim, retoma-se a classificação elaborada por Deleuze.

\section{As categorias fenomenológicas e primeiridade/qualissigno/ícone}

Conforme reflexões que constam em Drigo (2007) e em Drigo e Souza (2013), a Fenomenologia, para Peirce, uma das três divisões da Filosofia, é a quase-ciência que dá conta de todas as especificidades dos fenômenos, nos seus modos de aparecer, que ocorre antes da percepção, vista aqui como a porta de entrada das coisas do mundo, de fora, do exterior, para o interior, para a mente. Ela ocorre antes da cognição, ou a ação do signo, no caso, na mente humana. Peirce reduziu a variedade de fenômenos a apenas três elementos: a qualidade (relação monádica), a alteridade (relação diádica) e a mediação (relação triádica), que constituem as três categorias fenomenológicas: primeiridade, segundidade e terceiridade, respectivamente.

O primeiro modo do aparecer, dado pelas qualidades do fenômeno, é a primeiridade. As qualidades da cor, do som, do odor, do prazer estão presentes em fenômenos completos em si mesmos eque se constituem em livres possibilidades de experiência. A faculdade de ver é imprescindível para vivenciar qualidades do mundo tal como elas aparecem, para ler o mundo como aparência. A qualidade de sentimento é o representante psíquico dessa categoria."A primeira categoria, então, é Qualidade de Sentimento ou que quer que seja tal como é, positivamente, e sem relação com nada mais"(Peirce, 1931c, p. 23, tradução nossa)

A qualidade de sentimento é monádica, ou seja, não depende de outra coisa do mundo, em nenhum aspecto. A vermelhidão, por exemplo, existe sem que alguém possa imaginá-la ou percebê-la em uma realização, ou seja, ela existe independente de um confronto ou de uma ideia que a mente humana possa construir envolvendo-a. Assim, ela é livre, tem frescor. É pura possibilidade.

Outro modo do fenômeno aparecer é o da alteridade, da ação-reação, do embate, que caracteriza a ação entre duas coisas, mas sem mediação, sem envolver qualquer meio ou um terceiro. 
Estamos continuamente colidindo com o fato duro. Esperávamos uma coisa ou passivamente tomávamo-la por admissível e tínhamos sua imagem em nossas mentes, mas a experiência força esta ideia ao chão e nos compele a pensar muito diferentemente. (Peirce, 1931a, p. 106, tradução nossa).

O modo de aparecer objetual, a relação diádica, caracteriza a segundidade. A terceiridade, por sua vez, é mediação, relação tríadica, ou seja, é"a ideia daquilo que é tal qual é por ser um Terceiro ou Meio entre um Segundo e seu Primeiro." (Peirce, 1931c, p. 32, tradução nossa). As categorias sustentam a definição de signo e as classificações de signos propostas por Peirce.

Destacam-se, a seguir, conceitos que compõem a gramática especulativa, uma das três divisões da semiótica ou lógica, a ciência geral dos signos elaborada por Peirce. Um signo, como consta em Peirce (1931b) é qualquer coisa, que ao se reportar a um objeto, determina uma outra coisa, o interpretante e, do mesmo modo, ele se torna objeto quando o interpretante, por sua vez, se torna signo e gera outro interpretante e assim continua infinitamente. Essa definição mostra que a ação do signo, ou semiose, é infinita. Conforme Drigo e Souza (2013), o signo pode ser definido, como aquele que representa algo (o objeto) para a ideia que provoca ou modifica, o interpretante. Assim, o signo é um veículo que comunica à mente (nesse contexto, trata-se da mente humana) algo do exterior. Definir signo é, portanto, tratar de uma relação triádica constituída pelo signo, objeto e interpretante, tal como mostra o diagrama (Figura 1).

\section{- Figura 1 - A definição de signo em diagrama}

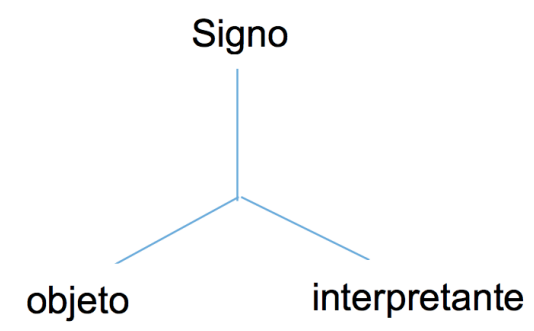

Fonte: Drigo (2007, p. 63).

O signo representa o objeto, sendo assim, ele está no lugar do objeto numa certa medida, sob certos aspectos, mas não é o próprio objeto. $O$ objeto, ao afetar uma mente, via signo, determina algo, o interpretante. Vale conferir essas explicações em outra definição de Peirce.

Defino um Signo como qualquer coisa que, de um lado, é assim determinado por um objeto e, de outro, assim determina uma ideia na mente de uma pessoa, esta última determinação, que denomino 
o Interpretante do signo é, desse modo, mediatamente determinada por aquele Objeto. Um signo, assim, tem uma relação triádica com seu Objeto e com seu Interpretante (Peirce, 1958, p. 82, tradução nossa).

No ato de apreender o fenômeno ou faneron - "o total coletivo de tudo aquilo que está de qualquer modo presente na mente, sem qualquer consideração se isto corresponde a qualquer coisa real ou não" (Peirce, 1931a, p. 93, tradução nossa), o pensamento necessariamente o converte em signos, depois deste passar pela percepção. Não há acesso ao mundo exterior, senão via signos.

No entanto, os signos, segundo Peirce (1931b), são divisíveis em três tricotomias: a primeira constitui-se com o fundamento do signo (o signo em relação a ele próprio), que pode ser uma qualidade, um existente, ou uma lei. A segunda, considera a relação do signo com seu objeto, se o signo guarda em si alguma característica do próprio objeto, se guarda alguma relação existencial com o objeto ou se a relação se faz com o interpretante. A terceira tricotomia se estabelece com o modo como o interpretante, via signo, mostra o objeto, se como possibilidade, fato, ou argumento. As três tricotomias são guiadas pelas categorias fenomenológicas.

Peirce (1931 b) esclarece que, de acordo com a primeira divisão, um signo pode ser denominado qualissigno, sinsigno, ou legissigno. Explica ainda que um qualissigno é uma qualidade que é um signo e que agirá como tal se a qualidade se incorporar, no entanto, não é a atualização da qualidade que o faz qualissigno.

Um sinsigno, em que a sílaba sin do termo sinsigno deve ser entendida como única, singular, conforme consta em Peirce (1931b), é uma coisa existente ou um evento que é um signo, no entanto, ele não é signo pelo fato de incorporar qualidades, embora elas sejam imprescindíveis, pois são elas, encarnadas numa forma, que tornam a coisa ou o evento um signo, ou mais especificamente, um sinsigno.

Um legissigno, segundo Peirce (1931b, p. 90, tradução nossa), "é uma lei que é um signo". Explica ainda que a lei é estabelecida por pessoas e que o objeto de um legissigno não é um objeto único, mas um tipo geral cujo significado depende de uma instância de aplicação da lei, de uma réplica, que é um sinsigno. "Assim, todo legissigno requer sinsignos. Mas, estes não são sinsignos comuns, pois são ocorrências de uma lei que são vistas como significativas" (Peirce, 1931b, p. 90, tradução nossa).

Com a segunda tricotomia, como consta em Peirce (1931b), o signo é classificado em ícone, índice e símbolo. Nas palavras de 
Pode haver uma mera relação da razão entre o signo e a coisa significada, nesse caso, o signo é um ícone. Ou pode haver uma ligação física direta, nesse caso, o signo é um índice. Ou pode haver uma relação que consiste no fato de que a mente associa o signo ao seu objecto, nesse caso, o signo é um nome (ou símbolo). (Peirce,1931a, p. 127, tradução nossa).

Conforme Peirce (1931b), na terceira tricotomia, um signo pode ser denominadorema, dicissigno (ou dicente), ou argumento. Esclareceainda que um rema é um signo que é entendido por representar um objeto possível e embora possa proporcionar alguma informação, a sua interpretação não depende disso. O dicissigno ou dicente, como encontra-se em Peirce (1931b), é um signo que, para seu interpretante, é um signo de existência real. Ele envolve necessariamente um rema, como uma parte dele, o que contribui para que seja interpretado como uma indicação. Assim, o rema é essencial para o dicente, mas não o constitui. Um argumento, por sua vez, é um signo que, para seu interpretante, é um signo de lei. Sobre a terceira tricotomia, nas palavras de Peirce (1931b, p. 91, tradução nossa):

Ou nós podemos dizer que um rema é um signo que é entendido por representar seu objeto pelas suas qualidades; que o dicissigno é um signo que é entendido por representar seu objeto como um existente; e que um argumento é um signo que é entendido por representar seu objeto como signo.

Para a compreensão do conceito de imagem-afeção, a definição de ícone é retomada.

\begin{abstract}
Um ícone é um signo que se refere ao objeto que denota meramente em virtude de seus próprios caracteres e que os possui, da mesma forma, no caso de tal objeto existir ou não. É verdade que a menos que haja realmente um tal objeto, o ícone não age como um signo; mas isso não tem nada a ver com seu caráter de signo. Qualquer coisa, seja qualidade, existente, ou lei, é um ícone de qualquer coisa, na medida em que é parecida com esta coisa e é usada como um signo dela (Peirce, 1931b, p. 90, tradução nossa).
\end{abstract}

Faz-se necessário retomar ainda as modalidades de ícone, para que as classificações elaboradas por Deleuze para a imagem-afeção possam ser revisitadas. “Uma possibilidade por si própria é um ícone puramente em virtude de sua qualidade; e seu objeto só pode ser uma Primeiridade (...). Mas um signo pode ser icônico, isto é, pode representar seu objeto por similaridade, não importa o seu modo de ser" (Peirce,1931b, p. 99, tradução nossa). 
Assim sendo, conforme Peirce (1931b), o ícone se divide em ícone puro e signo icônico ou hipoícone, sendo que esta última modalidade apresenta o objeto por similaridade. Se a similaridade for na aparência, o hipoícone denomina-se imagem. A segunda modalidade, aquela que representa as relações, principalmente diádicas das partes de uma coisa por relações análogas em suas próprias partes, é o diagrama. No diagrama não há nenhuma semelhança perceptível, como na imagem, há apenas analogia entre as relações das partes de cada um, do signo e do objeto (Fig. 2). A terceira modalidade é a metáfora, que representa similaridade de significados.

\section{Figura 2 - Modalidades de ícones}

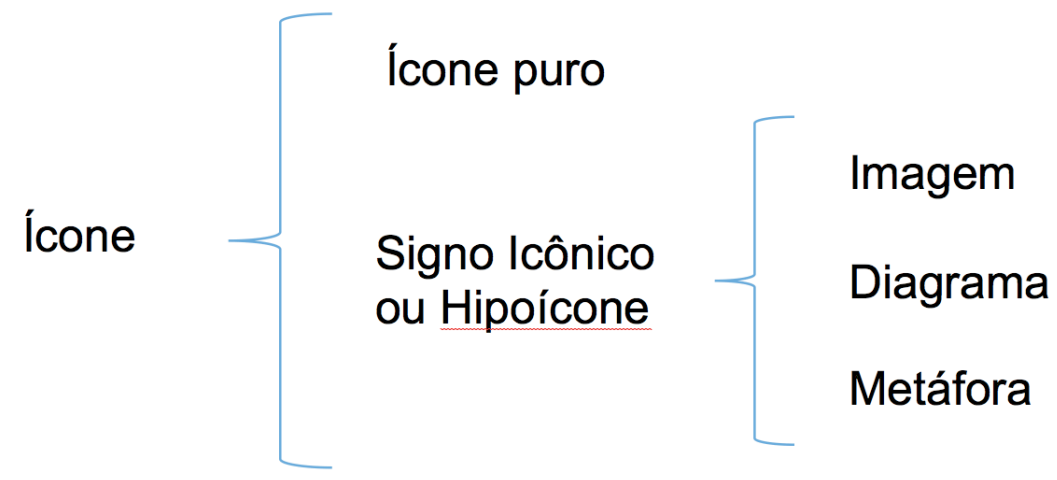

Fonte: Elaborado pela autora a partir de Peirce (1931b, p. 99-100).

Santaella e Nöth (2001) analisam com rigor as definições e exemplos de Peirce e propõem uma classificação que auxilia a compreensão das classificações empreendidas por Deleuze. Segundo os autores, há três modalidades de ícone: puro, atual e signo icônico ou hipoícone, que correspondem às divisões triádicas de Peirce, no caso, correspondendo a um primeiro, segundo e terceiro na seara da primeiridade. O ícone puro, conforme Santaella e Nöth (2001, p. 60), "é uma simples qualidade de sentimento indivisível e inanalisável. Só pode ter natureza mental, mas como possibilidade ainda não irrealizada não é nem mesmo comparável a uma ideia, apenas um flash de incandescência mental, quase-imagem interior".

Oícone atual, por suavez, quecorrespondeàsfunções do ícone no processo perceptivo, divide-se em ativo e passivo. O "aspecto passivo corresponde à ação do percepto sobre a mente ou ao lado passivo da mente, em estado de disponibilidade não reativa à apreensão do percepto" (Santaella; Nöth, 2001, p. 60-61), que manifesta-se de dois modos: como qualidade de sentimento e como revelação perceptiva. Segundo os mesmos autores, a qualidade de sentimento corresponde ao efeito de uma qualidade exterior, como cor, luz, cheiro ou 
outras, ou a uma mescla de efeitos de qualidades exterior e interior, como visão ou lembrança do efeito de uma dor, ou algo prazeroso que, em certa medida, provoca efeitos na mente, como algo que absorve o intérprete no lapso de tempo que dura. A revelação perceptiva corresponde a uma identidade formal entre o percepto e o percipuum, que implica numa identidade material entre ambos.

O aspecto ativo corresponde à instância ativa da mente. Segundo Santaella e Nöth (2001, p. 61), nesse nível, "o percepto aparece como qualidade e a tendência da mente é produzir associações sob a lei da similaridade". Ainda conforme os mesmos autores, são três as possibilidades: a primeira se dá quando um conjunto de qualidades junta-se na percepção numa só, como um amálgama de cores e formas, por exemplo; a segunda ocorre quando uma qualidade singular é tomada como objeto de outra qualidade singular e como exemplos pode-se mencionar analogias como o azul do céu e o azul dos olhos de uma pessoa. E, por fim, a terceira ocorre quando uma imagem de similaridade é adotada como uma regra geral, que pode ser coletivamente aceita.

Tratou-se anteriormente da outra modalidade de ícone, os signos icônicos ou hipoícones. Em seguida, as classificações dadas por Deleuze para a imagemafeção são retomadas.

\section{Revendo as classificações elaboradas por Deleuze}

Ao tratar da imagem-afeção, Deleuze descreve como a chuva pode ser um ícone puro, esclarecendo que não se trata do conceito de chuva, ou de uma chuva atualizada, mas da chuva como afeto, ou seja, como "um conjunto de singularidades que apresenta a chuva tal como ela é em si, puro poder ou qualidade que conjuga sem abstração todas as chuvas possíveis e compõe o espaço qualquer correspondente" (Deleuze, 2009, p. 171). No sentido peirceano, trata-se de uma qualidade de sentimento indivisível e não analisável, que apresenta-se como uma mera possibilidade ainda não realizada e de natureza mental. Pura primeiridade.

Outras modalidades de ícones são apresentadas com a rostificação, ou com o processo de transformar qualquer objeto em rosto. No exemplo dado por Deleuze, no caso do grande relógio, de um lado, se atualiza um ícone atual, no seu aspecto passivo, visto como revelação perceptiva, uma experiência que corresponde à identidade formal entre percepto e percipuum. Isto ocorre quando traços que escapam do contorno da coisa rostificada adquirem autonomia diante de outros. De outro, quando traços agrupam-se compondo um pensamento fixo, que perdura, um ícone puro atualiza-se.

Esses signos podem ser denominados qualissignos, pois são as qualidades que regem o processo de ação de signo. Peirce enfatiza que embora 
as qualidades estejam corporificadas, não é essa instância que predomina para tais signos. A imagem-afeção é qualissigno, embora apresente-se atualizada, como ocorre com a imagem cinematográfica.

Em relação ao objeto, esses signos são denominados ícones e podem apresentar-se como ícone puro, ou ícone atual, modalidade esta que envolve a atualização e refere-se às diferentes funções que o ícone adquire nos processos de percepção. São qualissignos icônicos remáticos. Os efeitos remáticos são decorrentes da seara da primeiridade, da consciência de qualidade que se instaura nesse movimento, ou derivado do estado de contemplação que prevalece para o intérprete.

Deleuze esclarece que outras imagens cinematográficas predominam como qualissignos, em relação ao seu fundamento e, em relação ao objeto que sugere, são ícones atuais, no seu aspecto passivo. As imagens cinematográficas de Antonioni, um dos maiores coloristas do cinema, para Deleuze (2009, p. 182), "servir-se-á das cores frias levadas até à sua máxima plenitude ou intensificação para ultrapassar a função absorvente, que mantinha ainda personagens e situações transformadas no espaço de um sonho ou um pesadelo". Tais imagens são qualissignos icônicos e os seus efeitos são os remáticos, que envolvem sensações de vacuidade e desconexão, conforme a classificação de Deleuze. Nestas imagens, o espaço é puro potencial e expõe poderes e qualidades puros, independentemente de onde e como se atualizam, ou se atualizaram, ou ainda vão se atualizar.

O objetivo do cinema de Antonioni é chegar ao não-figurativo, através de uma aventura cujo término é o eclipse do rosto, o apagamento das personagens. (...) é a cor que faz o confronto. É ela que eleva o espaço à potência do vazio, depois de se consumar a parte do que ela pode realizar-se no acontecimento. $O$ espaço não fica com isto despotencializado, mas pelo contrário tanto mais carregado de potencial (Deleuze, 2009, p. 183).

A imagem-afeção é a qualidade e o poder em potencial e o signo que lhe corresponde é a expressão elucida o filósofo. Sendo assim, a imagem-afeção predomina como qualissigno icônico remático.

O fato de predominar como uma modalidade ou outra de signo, implica que para um intérprete, uma imagem cinematográfica, embora do ponto de vista lógico ele tende a prevalecer como qualissigno icônico remático, nada impede que para um outro intérprete qualquer, essa imagem predomine como sinsigno indical dicente, pois diante da imagem o intérprete pode apenas identificá-la. Nesse sentido, as qualidades encarnadas nesse rosto não são 
apreendidas. A instância da primeiridade, ou da consciência da qualidade não se instaura. Apenas a segundidade, portanto, pode preponderar.

O fato de uma ou outra prevalecer, depende de como a relação entre a iconicidade e a indicialidade está engendrada na imagem, que corresponde às possibilidades da segundidade, com graus de degeneração.

Para fins de estabelecer estratégias metodológicas de análise para imagens em movimento, os modos como o signo sugere ou apresenta o objeto é o que determina os caminhos mais prováveis para a ação do signo, ou seja, o signo tem primazia lógica na semiose. A partir disto, vale pensar em estratégias que considerem a possibilidade da imagem cinematográfica prevalecer como imagem-afeção.

\section{Considerações finais}

A relevância da imagem-afeção para o pensamento com imagens, a partir de Eisenstein, conforme esclarece Deleuze, está no fato de que para o cineasta russo, essa modalidade de imagem propicia uma leitura afetiva do filme como um todo. A partir da aproximação dessas ideias de Deleuze às ideias peirceanas, constata-se a importância das categorias para a elaboração do conceito de imagem-afeção. Com isso, reafirma-se o potencial das imagens em que os aspectos qualitativos preponderam sobre os indiciais, ou sobre os que reportam o espectador ao real, ou ainda, sobre os compartilhados culturalmente, para suscitar a contemplação. Tais aspectos permitem que a seara da segundidade se amenize para que a primeiridade predomine.

O tecido qualitativo instaurado pelas imagens-afeção contribuem para firmar o pensamento, a cognição. Busca-se novamente contribuições nas análises dos fenômenos mentais elaboradas por Peirce, na perspectiva lógica, especificamente as que constam em A lei da mente, artigo publicado em 1892, conforme Machuco Rosa (1998). Delas advéma ideia de que quando as qualidades de sentimento preponderam, as ideias gerais tornam-se potencialmente presentes na semiose, pois são tais qualidades que as traduzem. Ou seja, esse tecido qualitativo é propício à cognição.

\section{REFERÊNCIAS}

BERGSON, Henri. Matéria e Memória: ensaio sobre a relação do corpo com o espirito. São Paulo: Martins Fontes, 1999.

DELEUZE, Gilles. A imagem-movimento Cinema 1. Lisboa: Assírio \& Alvim, 2009. 
A imagem-tempo Cinema 2. Editora Brasiliense, 2013.

DRIGO, Maria Ogécia. Comunicação e Cognição: semiose na mente humana. Porto Alegre: Sulina/EdUniso, 2007.

DRIGO, Maria Ogécia. Imagem cinematográfica e pensamento: a imagem-percepção na confluência de teorias de Deleuze e Peirce. Revista E-Compós, Brasília, v. 19, n. 2, maio/ago. 2016.

DRIGO, Maria Ogécia; SOUZA, Luciana. C. P. de. Aulas de semiótica peirceana. São Paulo: Annablume, 2013.

MACHADO, Roberto. Deleuze, a arte e a filosofia. Rio de Janeiro: Zahar, 2009.

MACHUCO ROSA, António (Ed.). Charles Sanders Peirce, Antologia Filosófica. Lisboa: Imprensa Nacional Casa da Moeda, Lisboa, 1998.

PEIRCE, Charles Sanders. Collected Papers. Hartshorne, Charles and Weiss, Paul (eds.), v. 1, Cambridge, Mass: Harvard University Press, 1931a.

. Collected Papers. Hartshorne, Charles and Weiss, Paul (eds.), v. 2, Cambridge, Mass: Harvard University Press, $1931 \mathrm{~b}$.

. Collected Papers. Hartshorne, Charles and Weiss, Paul (eds.), v. 5, Cambridge, Mass: Harvard University Press, 1931c.

. Collected Papers. Burks, Arthur W. (ed.), v. 8, Cambridge, Mass: Harvard University Press, 1958.

SANTAELLA, Lucia; NÖTH, Winfried. Imagem: Cognição, Semiótica, Mídia. São Paulo: Iluminuras, 2001.

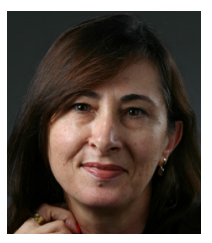

Dados da autora:

Maria Ogécia Drigo | maria.ogecia@gmail.com

Universidade de Sorocaba.

Universidade de Sorocaba (Uniso).

Doutora em Comunicação e Semiótica pela PUC/SP e Pós-doutora pela

ECA/USP. Docente e Coordenadora do Programa de Pós-Graduação em Comunicação e Cultura da

Endereço da autora:

Cidade Universitária Professor Aldo Vannucchi - Rod. Raposo Tavares, Km 92.5 - Cep: 18023-000 -

Sorocaba, SP - Brasil 